\title{
Chordoid Meningioma: Case Report and Review of the Literature
}

\author{
Marek Prokopienko ${ }^{1 *}$, Teresa Wierzba-Bobrowicz², Wiesława Grajkowska², Tomasz Stępieñ ${ }^{2}$ and Michał \\ Sobstyl ${ }^{1}$ \\ ${ }^{1}$ Department of Neurosurgery, Institute of Psychiatry and Neurology, Warsaw, Poland \\ ${ }^{2}$ Department of Neuropathology, Institute of Psychiatry and Neurology, Warsaw, Poland

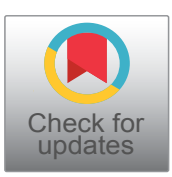

*Corresponding author: Marek Prokopienko, Department of Neurosurgery, Institute of Psychiatry and Neurology, Warsaw, Poland, Sobieskiego 9 Street 02-957 Warsaw, Poland

\begin{abstract}
Chordoid meningioma is an uncommon histopathological type of meningioma, frequently associated with Castleman's syndrome. Histologically, chordoid meningiomas are similar to chordomas. Because of their high proliferative index, they present aggressive biological behavior and high risk of postoperative recurrence. We report a case of choroid meningioma in adult patient without Castleman's syndrome manifestation. As its chordoid features is related with a rapid recurrence after incomplete removal, meticulous histopathological examination is crucial for the adequate postoperative treatment plan.
\end{abstract}

\section{Keywords}

Chordoid meningioma, Mitotic index, Castleman's disease

\section{Introduction}

Meningioma is the most common benign intracranial tumor, representing $13-36 \%$ of all primary central nervous system neoplasms. Among meningiomas $90 \%$ of tumors are benign [1,2]. Starting form 2007 all meningiomas with cortical invasion became considered as grade II [3]. This increased the rate of these meningiomas from $5 \%$ to $20-35 \%$ [3]. Among grade II group, besides atypical and clear cell meningiomas, the rare type of these tumors constitutes chordoid meningiomas (CM). CMs represent approximately less than $1 \%$ of intracranial meningiomas [4-6]. The term chordoid meningioma was initially presented by Kepes, et al. [7] who defined it as having a chordoma-like histologic appearance with a clustering of tumor cells. We report a 71-years-old pa- tient with chordoid meningioma in parasagittal region infiltrating the superior sagittal sinus and motor cortex of the left hemisphere.

\section{Case Report}

A 71-years-old non-smoking right-handed woman, presented with two months history of progressive left leg paresis. Cranial magnetic resonance imaging (MRI) revealed a $3 \times 4 \times 4 \mathrm{~cm}$ mass in the left occipital region with superior sagittal sinus infiltration (Figure $1 \mathrm{~A}$ and Figure 1B).

Two weeks after the initial presentation, she underwent the left fronto-parietal craniotomy. Considering the superior sagittal sinus infiltration by the tumor, advanced age of the patient, a subtotal tumor resection was undertaken. Small tumor remnants within the sinus cavity were coagulated thoroughly. The infiltration of the arachnoid by the tumor increased the cerebral cortex injury. Left lower limb paresis progression was observed immediately after the procedure, and it subsequently diminished during the rehabilitation. Control magnetic resonance imaging carried out one month after surgery confirmed tumor remnants within the superior sagittal sinus cavity (Figure $1 \mathrm{C}$ and Figure 1D). The patient was consulted by oncologist and stereotactic radiotherapy (Cyberknife) was applied to irradiate the remnants of the tumor within the superior sagittal sinus. No tumor tissue progression was observed six months after surgery (Figure $1 \mathrm{E}$ and Figure 1F).

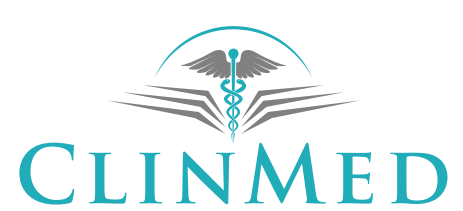

INTERNATIONAL LIBRARY

Citation: Prokopienko M, Wierzba-Bobrowicz T, Grajkowska W, Stępień T, Sobstyl M (2020) Chordoid Meningioma: Case Report and Review of the Literature. Neurosurg Cases Rev 3:045. doi. org/10.23937/2643-4474/1710045

Accepted: November 14, 2020; Published: November 16, 2020

Copyright: () 2020 Prokopienko M, et al. This is an open-access article distributed under the terms of the Creative Commons Attribution License, which permits unrestricted use, distribution, and reproduction in any medium, provided the original author and source are credited. 

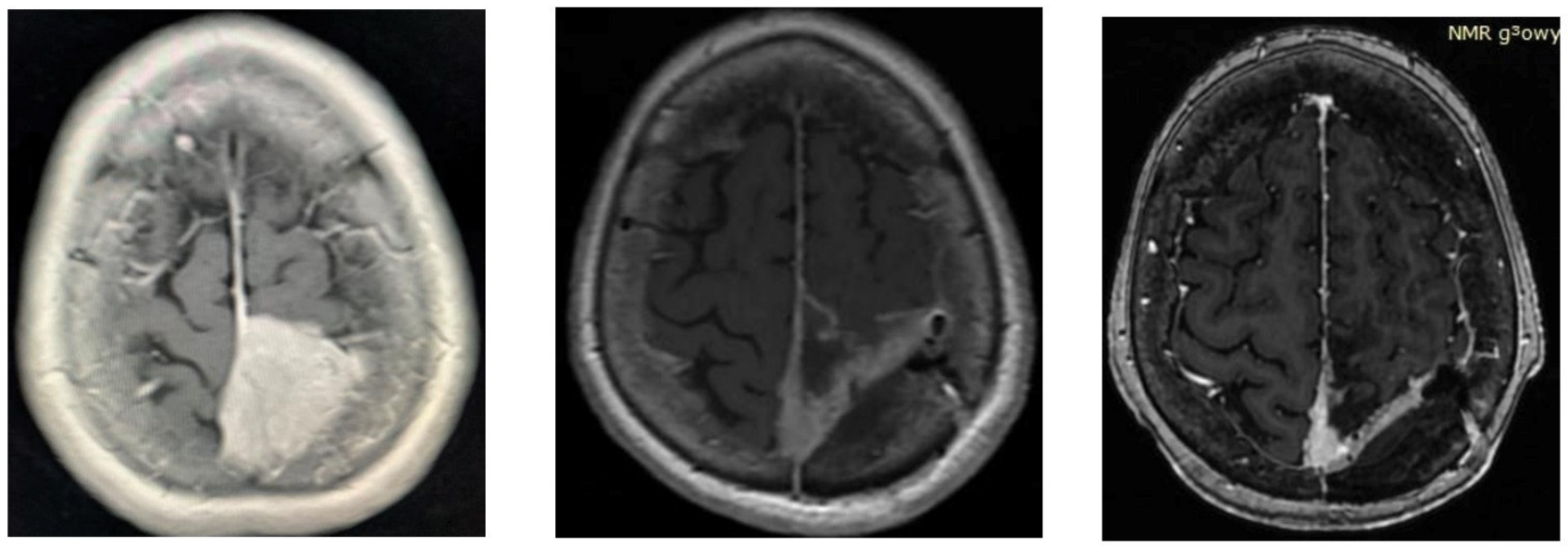

A.

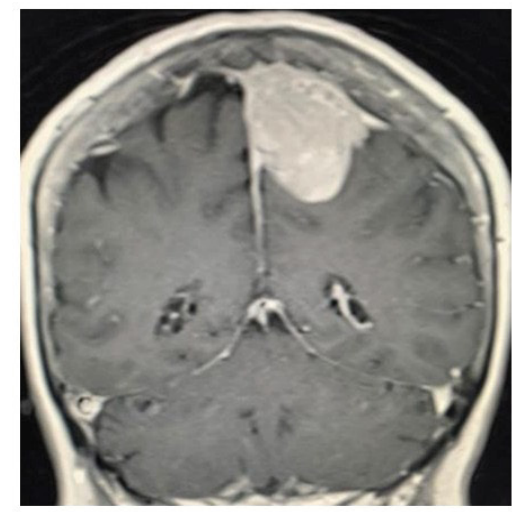

B.
C.

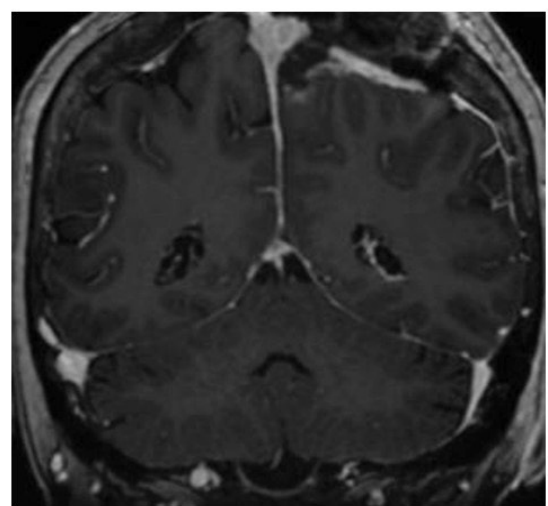

D.
E.

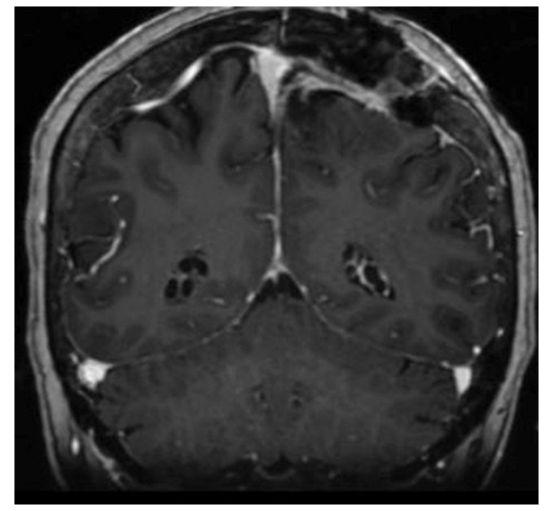

F.

Figure 1: $(A, B) M R I$ scans showing Choroid Meningioma in axial and sagittal plane before surgery; (C,D) MRI scans showing tumor remnants in the superior sagittal sinus one month after surgery, before Gamma Knife therapy; (E,F) MRI scans six months after surgery, recently after Gamma Knife therapy.

\section{Material and Methods}

The samples tissue from neurosurgical procedure were fixed in $10 \%$ buffered formalin and paraffin embedded. The specimens were stained with hematoxylin-eosin and mucicarmine methods. Immunohistochemical studies were performed with antibodies to epithelial membrane antigen (EMA) (1:200, Leica clone GP1,4), cytokeratin, CK (1:50, DACO clone AE1/AE3), glial fibrillary acid protein, GFAP (1:300, Bio-Rad, clone 1B4), Ki-67 (1:75, Invitrogen, clone SP6). The sections were examined and photographed.

\section{Microscopic examination}

Neuropathological examination revealed that samples of the tumor were composed of cords of round, ovoid and epithelial cells, embedded in a prominent myxoid background (Figure 2A, Figure 2B and Figure 2D). Sometimes, mild nuclear atypia was focally present. The conventional meningothelial or transitional morphology was visible in small fields (Figure 2C). Immunohistochemical staining showed positive staining for epithelial membrane antigen (EMA) (Figure 2E). The Ki-67 labeling index was about $8 \%$ (Figure 2F). The tumor cells were negative for glial fibrillary acid protein (GFAP) and cytokeratin (CK). Based on these findings, a final diagnosis of Choroid meningioma (WHO GII) was made.

As the tumor removal was subtotal, patient age did not encouraged us to further resection, decision about complementary therapy was made in agreement with oncologist.

\section{Discussion}

Chordoid meningiomas are very rare tumors, as they represent only $0.5 \%$ of all meningiomas. Less than 300 cases were reported worldwide up to the date. Kepes, et al. [7], who first described these lesions, reported their association with Castleman's syndrome. Couce, et al. [5] concluded that the systemic disease associated with chordoid meningiomas was restricted to children. No manifestation of systemic disease in adults was noted in his material.

Histologically, chordoid meningiomas are similar to chordomas. They contain trabeculae, or cords of eosinophilic vacuolated cells in a myxoid matrix [8]. High 


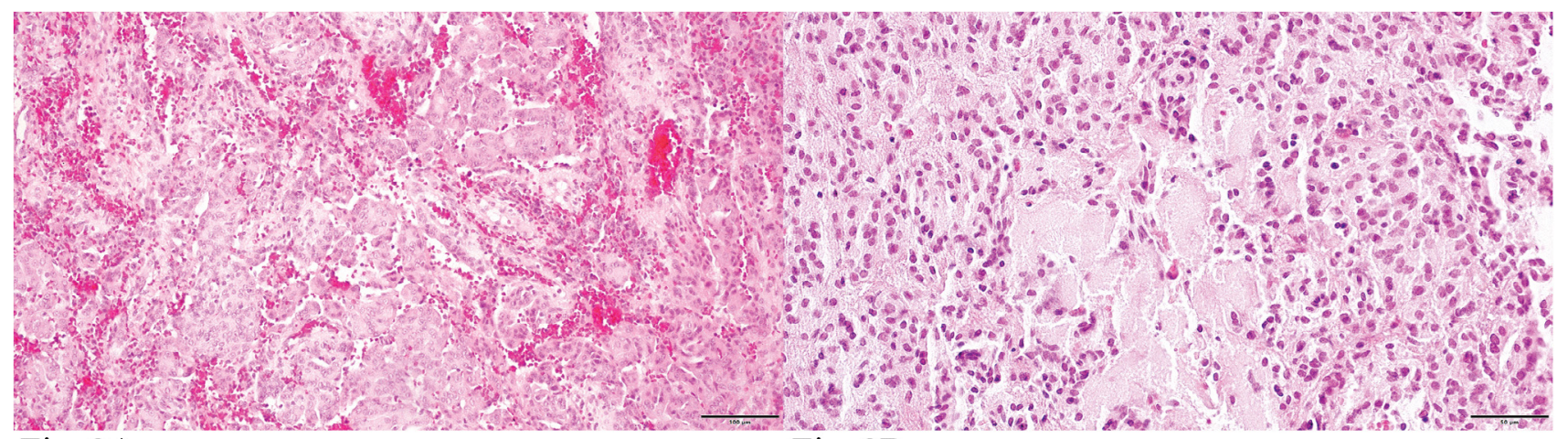

Fig. 2A.

Fig. 2B.

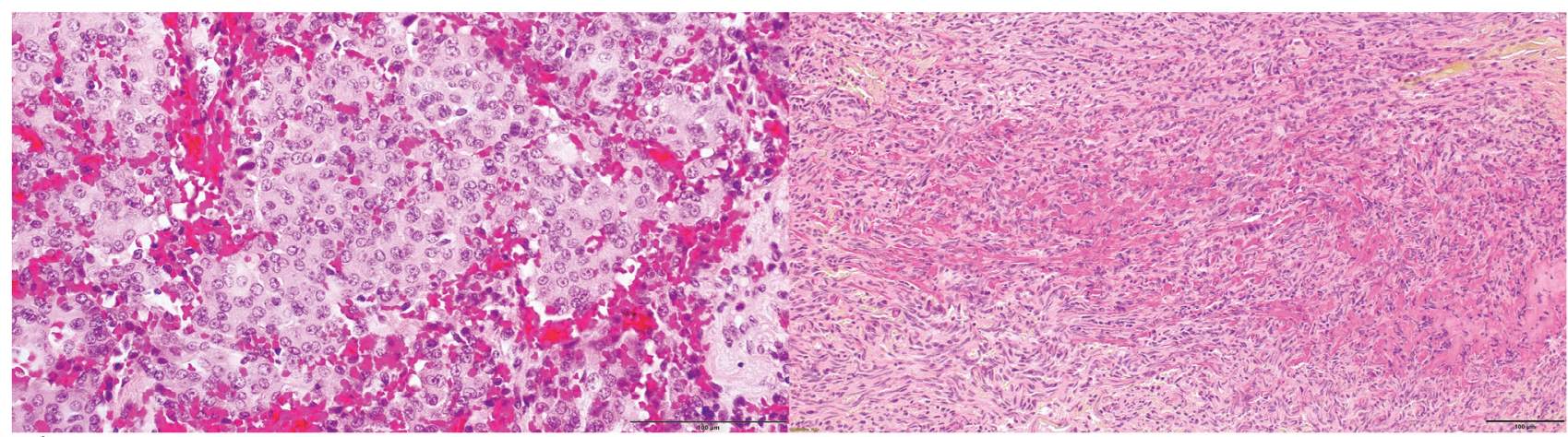

Fig. 2C

Fig. 2D.

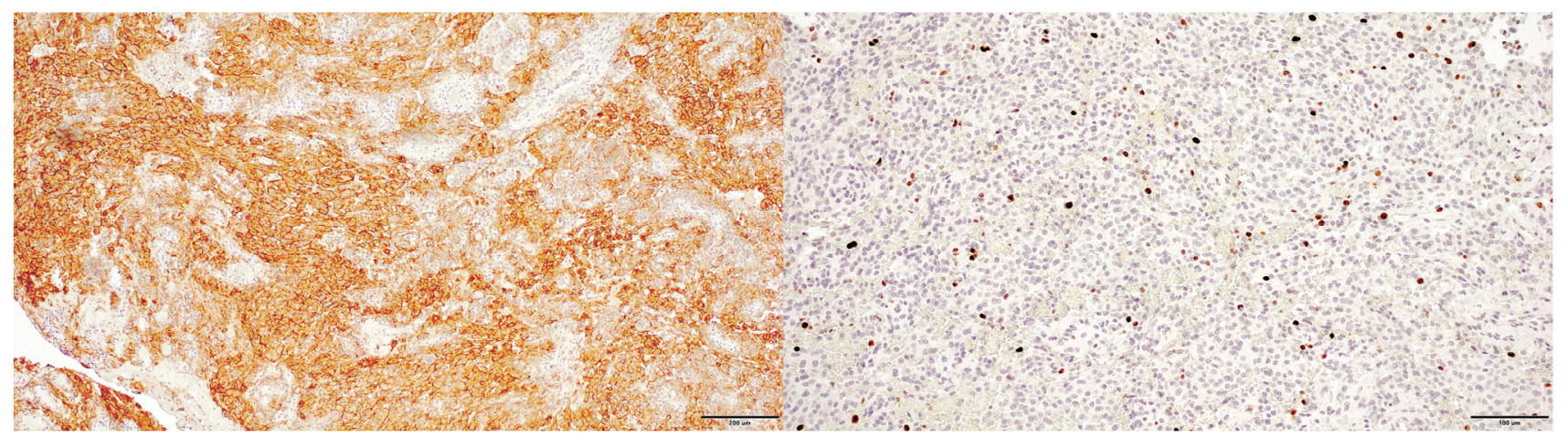

Fig. 2E

Fig. 2F.

Figure 2: Neuropathological features of choroid meningioma with haemorrhage. (2A) Cords of tumor cells and trabeculae of round, ovoid and epithelial cells. H\&E; (2B) The tumor cells were embedded in a prominent myxoid background. H\&E; (2C) Typical meningothelial areas with haemorrhage. H\&E; (2D) Tumor cells embeded in mucinous stroma. Mucicarmine;

(2E) Cords of tumor cells with intense EMA immunoreactivity; (2F) Ki-67 labeling index shows nuclear immunoreactivity.

mitotic rate, increased cellularity, small cell change, sheet like growth, macro nucleoli and focal necrosis are present [3,9]. Loewenstern, et al. [9] noticed moreover, that the mitotic index is a direct indicator of cell proliferation and predictor of tumor behavior. Aghi, et al. [10] reported that prominent nucleoli were associated with higher risk of recurrence. In material of Lee, et al. [11] focal necrosis was related with six-fold risk of recurrence. Baltus, et al. [12] found, that detection of chromothripsis in chordoid meningioma can be related with considerable potential of recurrence after initial surgery. One of the most important regrowth patterns of the tumor is the high chordoid features percentage. It was first described by Couce, et al. [5]. Chordoid features greater than $50 \%$ as a significant tumor regression marker was emphasized also in later reports [13-16]. In the study of Matyja, et al. [17] significant chordoid component was concerned not only with high tumor recurrence rate, but also with more aggressive biological behavior. Hasegawa, et al. [8] described relation with high mucoid quality of the tumor with its rapid spread and recurrence.

As the extent of resection is the most important prognostic factor in case of chordoid meningioma treatment, Gross total resection (GTR) should be the goal for the surgical management of primary chordoid meningioma. It remains the strongest predictor of long-term rates of tumor control [4-9,15-20]. As the recurrence remains high following subtotal resection, careful follow up should be recommended in every case. The most illustrative reason for careful observation was presented by Couce, et al. [5]. In his long term follow up, all patients after a subtotal resection experienced tumor recurrence, while only 1 out of the 29 patients after 
gross total resections recurred [5]. Similar observations were noticed in the study of Zhu, et al. [21]. Although the most of authors recommend adjuvant radiotherapy for atypical meningiomas in the management of residual disease following subtotal resection $[14,22,23]$, its efficacy remains unclear. In cases of incomplete resections, Liu, et al. [24] justified its application as a method of salvage treatment. Conversely, in cases of complete tumor resections, most of the authors found no significant progression free survival rates increase after radiotherapy [4,13,21-24]. Only few case studies advocated for the role of radiotherapy after Gross total resection $[25,26]$.

The MIB-LI (cell proliferation marker) is a histological marker for proliferative capacity, correlated with high rates of tumor control [4]. Higher MIB-LI has been noted to correlate with recurrent meningiomas in studies of some authors [27-30]. Others did not share this opinion, founding no correlation with outcomes $[13,30,31]$.

Other factors concerned with unfavorable overall results were presented by Zhang, et al. [32]. In this large retrospective analysis, male gender, larger tumor size, surgical history and bone invasion were defined as risk factors associated with poor outcome.

\section{Conclusions}

Choroid meningiomas constitute a rare and diverse subtype of WHO grade II meningiomas. The review of the literature evidenced, that the most important factor leading to progression free survival is gross total resection. The role of adjuvant radiotherapy remains controversial. It should be indicated in patients with subtotal resection and high MIB-LI.

\section{References}

1. Poulen G, Vignes J-R, Le Corre M, Loiseau H, Bauchet L (2020) WHO grade II meningioma: Epidemiology, survival and contribution of postoperative radiotherapy in a multicenter cohort of 88 patients. Neurochirurgie 66: 73-79.

2. Champeaux Ch, Dunn L (2016) World health organization grade II meningioma: A 10-year retrospective study for recurrence and prognostic factor assessment. World Neurosurg 89: 180-186.

3. Louis DN, Ohgaki H, Wiestler OD, Cavenee WK, Burger PC, et al. (2007) The 2007 WHO classification of tumours of the central nervous system. Acta Neuropathol 114: 97109.

4. Choy W, Ampie L, Lamano JB, Kesavabhotla K, Mao Q, et al. (2016) Predictors of recurrence in the management of chordoid meningioma. J Neurooncol 126: 107-116.

5. Couce ME, Aker FV, Scheithauer BW (2000) Chordoid meningioma: A clinicopathologic study of 42 cases. The American Journal of Surgical Pathology 24: 899-905.

6. Epari S, Sharma MC, Sarkar C, Garg A, Gupta A, et al. (2006) Chordoid meningioma, an uncommon variant of meningioma: A clinicopathologic study of 12 cases. Journal of Neuro-oncology 78: 263-269.

7. Kepes JJ, Chen WY, Connors MH, Vogel FS (1988) Chor- doid" meningeal tumors in young individuals with peritumoral lymphoplasmacellular infiltrates causing systemic manifestations of the Castleman syndrome. A report of seven cases. Cancer 62: 391-406.

8. Hasegawa S, Yoshioka S, Urabe S, Kuratsu J (2006) Rapidly enlarging chordoid meningioma with abundant mucin production. Neuropathology 26: 438-441.

9. Loewenstern J, Shuman W, Rytland JW, Kessler RA, Kohli $\mathrm{KM}$, et al. (2019) Preoperative and histological predictors of recurrence and survival in atypical meningioma after initial gross total resection. World Neurosurgery.

10. Aghi MK, Carter BS, Cosgrove GR, Ojeman RG, Amin-Hanjani S, et al. (2009) Long-term recurrence rates of atypical meningiomas after gross total resection with or without postoperative adjuvant radiation. Neurosurgery 64: 56-60.

11. Lee KD, DePowell JJ, Air LL, Dwivedi AK, Kendler A (2013) A typical meningiomas: Is postoperative radiotherapy indcated? Neurosurg Focus 35.

12. Baltus C, Toffoli S, London F, Delreee P, Gilliard C, et al. (2019) Chromothripsis in an early recurrent chordoid meningioma. World Neurosurg 130: 380-385.

13. Di leva A, Laiq S, Nejad R, Schmitz EM, Fathalla H, et al. (2014) Chordoid meningiomas: Incidence and clinicopathological features of a case series over 18 years. Neuropathology.

14. Lin JW, Ho JT, Lin YJ, Wu YT (2010) Chordoid meningioma: A clinicopathologic study of 11 cases at a single institution. J Neurooncol 100: 465-473.

15. Mitsuhashi T, Ono S, Inohara T, Otomo T, Aoki A, et al. (2006) Chordoid meningioma--case report. Neurol Med Chir 46: 37-40.

16. Donato G, Ferraro G, Signorelli F, lofrida G, Lavano A, et al. (2006) Chordoid meningioma: Case report and literature review. Ultrastruct Pathol 30: 309-314.

17. Ewa Matyja E, Grajkowska W, Lazarczyk M, Marchel A, Czernicki T (2006) Chordoid meningiomas of a different histopathological pattern. A report of two cases. Folia Neuropathol 44: 34-41.

18. Mawrin C, Perry A (2010) Pathological classification and molecular genetics of meningiomas. J Neurooncol 99: 379-391.

19. Arima T, Natsume A, Hatano $H$, Nakahara $N$, Fujita $M$, et al. (2005) Intraventricular chordoid meningioma presenting with Castleman disease due to overproduction of interleukin-6. Case report. Journal of Neurosurgery 102: 733-737.

20. Mclver JI, Scheithauer BW, Atkinson JL (2005) Deep sylvian fissure chordoid meningioma: Case report. Neurosurgery.

21. Zhu HD, Chen H, Xie Q, Gong Y, Mao Y, et al. (2013) Chordoid meningioma: A retrospective study of 17 cases at a single institution. Chinese Medical Journal 126: 789-791.

22. Hug EB, Devries A, Thornton AF, Munzenride JE, Pardo FS, et al. (2000) Management of a typical and malignant meningiomas: Role of high-dose, 3D- conformal radiation therapy. J Neurooncol 48: 151-160.

23. Lo SS, Cho KH, Hall WA, Kossow RJ, Hernandez WL, et al. (2002) Single dose versus fractionated stereotactic radiotherapy for meningiomas. Can J Neurol Sci 29: 240-248.

24. Liu X, Shan B, Wang M, Xu J (2018) World health organization grade II meningiomas: The role of adjuvant/salvage gamma knife surgery after initial surgery and prognostic factor assessment. World Neurosurg 109: e352-e362. 
25. Moiyadi AV, Sridhar E, Gupta T, Ramadwar M (2010) A primary optic nerve sheath chordoid meningioma. J Clin Neurosci 17: 397-399.

26. Nambiar A, Pillai A, Parmar C, Panikar D (2012) Intraventricular chordoid meningioma in a child: Fever of unknown origin, clinical course, and response to treatment. J Neurosurg Pediatr 10: 478-481.

27. Yew A, Trang A, Nagasawa DT, Spasic M, Choy W, et al. (2013) Chromosomal alterations, prognostic factors, and targeted molecular therapies for malignant meningiomas. Journal of Clinical Neuroscience 20: 17-22.

28. Sandberg MM, Hirvonen HE, Elima KJ, Vuorio El (1993) Co-expression of collagens II and XI and alternative splicing of exon 2 of collagen II in several developing human tissues. The Biochemical journal 294: 595-602.
29. Whittle IR, Smith C, Navoo P, Collie D (2004) Meningiomas. Lancet 363: 1535-1543.

30. Jee TK, Jo KI, Seol HJ, Kong DS, Lee JI, et al. (2014) Clinical features and treatment outcome of chordoid meningiomas in a single institute. J Korean Neurosurg Soc 56: 194-199.

31. Wang XQ, Mei GH, Zhao L, Li ST, Gong Y, et al. (2013) Clinical features and treatment of intracranial chordoid meningioma: A report of 30 cases. Histopathology 62: 10021017.

32. Zhang G-J, Zhang Y-S, Zhang G-B, Yan X-J, Li C-B, et al. (2018) Prognostic factors, survival, and treatment for intracranial world health organization grade ii chordoid meningiomas and clear-cell meningiomas. World Neurosurgery. 